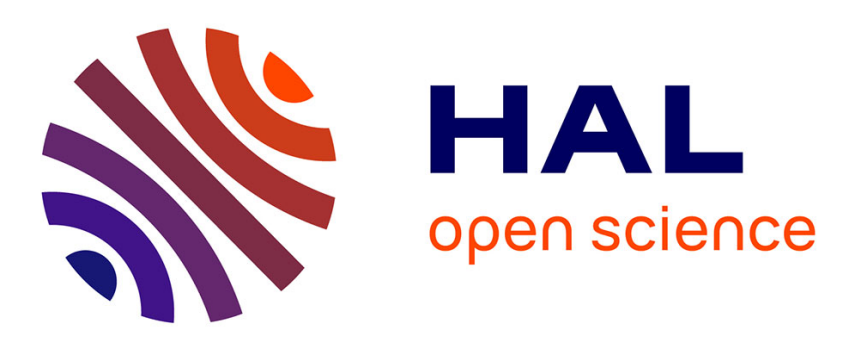

\title{
Paracapillaria (Paracapillaria) gastrica n. sp. (Nematoda: Capillariidae) from the marine fish Synodus variegatus Lacépède (Synodontidae, Aulopiformes) off New Caledonia
}

František Moravec, Jean-Lou Justine

\section{To cite this version:}

František Moravec, Jean-Lou Justine. Paracapillaria (Paracapillaria) gastrica n. sp. (Nematoda: Capillariidae) from the marine fish Synodus variegatus Lacépède (Synodontidae, Aulopiformes) off New Caledonia. Systematic Parasitology, 2020, 97 (2), pp.157-163. 10.1007/s11230-020-09907-7. hal-02558414

\section{HAL Id: hal-02558414 \\ https://hal.science/hal-02558414}

Submitted on 29 Apr 2020

HAL is a multi-disciplinary open access archive for the deposit and dissemination of scientific research documents, whether they are published or not. The documents may come from teaching and research institutions in France or abroad, or from public or private research centers.
L'archive ouverte pluridisciplinaire HAL, est destinée au dépôt et à la diffusion de documents scientifiques de niveau recherche, publiés ou non, émanant des établissements d'enseignement et de recherche français ou étrangers, des laboratoires publics ou privés. 
Systematic Parasitology 97, 157-163 (2020)

DOI: $10.1007 / \mathrm{s} 11230-020-09907-7$

ZooBank: urn:lsid:zoobank.org:pub:8055FCC1-2B23-478F-BAE4-3B92A4A68AD8

Paracapillaria (Paracapillaria) gastrica n. sp. (Nematoda: Capillariidae) from the marine fish Synodus variegatus Lacépède (Synodontidae, Aulopiformes) off New Caledonia

František Moravec * \& Jean-Lou Justine

\begin{abstract}
Based on light and scanning electron microscopical studies, a new nematode parasite, Paracapillaria (Paracapillaria) gastrica n. sp. (Capillariidae), is described from the stomach of the marine fish (variegated lizardfish) Synodus variegatus (Lacépède) (Aulopiformes: Synodontidae) from off New Caledonia. This species is mainly characterised by the length of the spicule $(267 \mu \mathrm{m})$, the proximal spicule end expanded to form a conspicuous folded, lobular rim, the presence of a well-developed caudal bursa supported by two lateral projections (rays) not adhering to the posterior border of body and by the size of eggs (54-60 $924-27 \mu \mathrm{m})$ with non-protruding polar plugs. Paracapillaria gastrica n. sp. is the first known capillariid species parasitic in a host belonging to the fish order Aulopiformes and the first species of this genus reported from fishes in New Caledonian waters and the South Pacific Ocean.
\end{abstract}

* Corresponding author

F. Moravec

Institute of Parasitology, Biology Centre of the Czech Academy of Sciences, Branišovská 31, 37005 České Budějovice, Czech Republic

e-mail: moravec@paru.cas.cz

J.-L. Justine

Institut Systématique Évolution Biodiversité (ISYEB), Muséum National d'Histoire Naturelle, CNRS, Sorbonne Université, EPHE, Université des Antilles, rue Cuvier, CP 51, 75005 Paris, France. e-mail: justine@mnhn.fr 


\section{Introduction}

Capillariid nematodes (Capillariidae) are frequent parasites of marine fishes, but because the present system of their genera is principally based on the morphology of males (Moravec \& Beveridge, 2017), the generic and species identification of these parasites is impossible if only females are found. Therefore, in the ichthyoparasitological literature, many capillariids from marine fishes are reported only as Capillariidae gen. sp. or within Capillaria Zeder, 1800 (sensu lato).

To date, only three nominal capillariid species are reported from marine fishes off New Caledonia, Capillaria plectropomi Moravec \& Justine, 2014 from Plectropomus leopardus (Lacépède) (Serranidae, Perciformes), Pseudocapillaria echenei (Parukhin, 1967) from Echeneis naucrates Linnaeus (Echeneidae, Perciformes) and Pseudocapillaria novaecaledoniensis Moravec \& Justine, 2010 from Pristipomoides argyrogrammicus (Valenciennes) (Lutjanidae, Perciformes) (Justine et al., 2010; Moravec \& Justine, 2010, 2014). However, probably an additional seven unidentified species, mostly designated as Capillariidae gen. spp., were reported from bony fishes of the orders Aulopiformes (Synodontidae), Perciformes (Acanthuridae, Carangidae, Haemulidae and Siganidae) and Syngnathiformes (Fistulariidae), and from the shark Stegostoma fasciatum (Hermann) (Orectolobiformes, Stegostomidae) (Moravec, 2001a; Justine et al., 2010; Moravec \& Justine, 2010; Moravec et al., 2016).

Recent examination of nematodes collected by J.-L. Justine and his students in the marine fish Synodus variegatus (Lacépède) from off New Caledonia in 2009 revealed the presence of a new species of Paracapillaria Mendonça, 1963 (Capillariidae), which is described below.

\section{Materials and methods}

Fish were caught by line and hook. Nematodes were collected by the wash method (Justine et al., 2012a). The nematodes were fixed in hot $4 \%$ formalin and $100 \%$ ethanol. For light microscopical examination (LM), they were cleared with glycerine. Drawings were made with the aid of a Zeiss microscope drawing attachment. Specimens used for scanning electron microscopical examination (SEM) were post-fixed in $1 \%$ osmium tetroxide (in phosphate buffer), dehydrated through a graded acetone series, critical-point- dried and sputter-coated with gold; they were examined using a JEOL JSM-7401F scanning electron microscope at an accelerating voltage of $4 \mathrm{kV}$ (GB low mode). All measurements are in micrometres unless otherwise indicated. The fish nomenclature adopted follows FishBase (Froese \& Pauly, 2019). 
Family Capillariidae Railliet, 1915

Genus Paracapillaria Mendonça, 1963

\section{Paracapillaria gastrica n. sp.}

Type-host: Synodus variegatus (Lacépède) (Aulopiformes: Synodontidae), variegated lizardfish.

Type-locality: Near Récif Toombo, off Nouméa, New Caledonia (collected 23.ii.2009).

Type-material: Holotype and allotype (mounted on SEM stub) in the Helminthological Collection of the Institute of Parasitology, Biology Centre of the Czech Academy of Sciences, České Budějovice (Cat. No. N- 1207); paratypes in the Muséum National d'Histoire Naturelle, Paris (MNHN JNC3117A and JNC3117B).

Prevalence, intensity and details about fish: 1 fish infected out of 8 fish examined; 18 nematode specimens. The infected fish, parasitological number JNC3117, was $290 \mathrm{~mm}$ in total length and $108 \mathrm{~g}$ in weight. The fish specimen was sent to the Museum and Art Gallery Northern Territory, Darwin, Australia, and was registered in the collections under number S.17127-001.

Site in host: Stomach.

Etymology: The species name gastrica (gastricus = gastric, stomachal) is a Latin adjective and relates to the fact that this nematode is parasitic in the host's stomach.

Description (Figs. 1, 2)

General. Small filiform nematodes. Anterior end narrow, rounded; exact number and distribution of cephalic papillae not established, probably 12 papillae arranged in 2 circles present as in some related species (Fig. 2A). Cuticle finely transversely striated (Fig. 2B). Two lateral bacillary bands distinct, fairly wide, extending along almost whole body length (Figs. 1H, 2F). Muscular oesophagus relatively long (Fig. 1A). Stichosome consisting of 32-42 stichocytes subdivided usually (mainly in posterior part of stichosome) into several transverse annuli; nuclei of stichocytes large; some stichocytes darker than others, this difference being indistinct in cleared specimens (Fig. 1B, C). Nerve-ring encircling muscular oesophagus at about its 1 st fourth. Two small wing-like cells present at oesophago-intestinal junction (Fig. 1B).

Male [Based on 1 specimen, holotype.] Length of body $6.17 \mathrm{~mm}$, maximum width 63 . Width of lateral bacillary bands 15. Length of entire oesophagus $2.64 \mathrm{~mm}$ (43\% of body length). Length of muscular oesophagus 324, of stichosome $2.31 \mathrm{~mm}$; number of stichocytes 36 . Nerve-ring situated 90 from anterior extremity. Seminal vesicle elongate, 384 long (Fig. 1F). Spicule well sclerotised, with almost smooth surface, 267 long (Fig. 1F, G). Proximal end of spicule distinctly expanded and 
provided with folded, lobular rim, distal end rounded (Fig. 1K-M); width of spicule at proximal and distal ends 7 and 6, respectively. Spicular canal not developed. Surface of spicular sheath smooth, without spines. Tail rounded, long, provided with cuticular membrane forming bursa. Bursa supported by 2 wide lateral digital projections (rays) curved to median line in ventral view. One pair of large spherical subventral papillae present at base of lateral projections, at about level of cloacal opening (Figs. 1D-G, 2C-E) Length of whole bursa in ventral view 15 , its maximum width 42 . Lateral caudal alae absent.

Female [Based on 10 ovigerous specimens; measurements of allotype in parentheses.] Body length 11.74-15.87 (13.72) $\mathrm{mm}$, maximum width 72-102 (90). Width of lateral bacillary bands 36-45 (36). Entire oesophagus 3.33-4.36 (3.93) mm, forming 25-29 (29)\% of body length. Length of muscular oesophagus 282-387 (384), of stichosome 3.05-3.99 (3.55) mm; stichocytes 32-45 (41) in number. Nerve- ring 81-105 (84) from anterior extremity. Vulva situated 30-81 (51) posterior to level of esophagointestinal junction at 3.44-4.39 (3.97) mm from anterior extremity, representing 26-29 (29)\% of entire body length; vulval lips not elevated or anterior lip slightly elevated (Fig. 1B). Eggs arranged usually in single file in uterus, rarely in 2 files. Eggs oval, slightly narrowed equatorially, polar plugs not protruding; egg wall 3-layered; inner layer hyaline, outer layer of eggs in uterus with fine, almost indistinct sculpture on surface (Fig. 1J). Size of eggs 54-60 x 24-27 (57-60 x 24-27), thickness of egg wall 3 (3); polar plugs 3-6 (5-6) long and 5-6 (6) wide. Content of fully developed eggs uncleaved. Caudal end rounded, anus slightly subterminal; tail 3-6 (3) long (Figs. 1I, N, 2F, G). Length of rectum 45-90 (45).

\section{Remarks}

According to Moravec \& Beveridge (2017), ten capillariid genera comprise parasites of freshwater, marine and brackish-water teleost fishes and elasmobranchs: Capillaria Zeder, 1800 (sensu stricto); Capillostrongyloides Freitas \& Lent, 1935; Freitascapillaria Moravec, 1982; Gessyella Freitas, 1959; Lobocapillaria Moravec \& Beveridge, 2017; Paracapillaria Mendonça, 1963; Paracapillaroides Moravec, Salgado-Maldonado \& Caspeta-Mandujano, 1999; Piscicapillaria Moravec, 1982; Pseudocapillaria Freitas, 1959; and Schulmanela Ivashkin, 1964. Nevertheless, Capillostrongyloides and Paracapillaria are distinguished solely by the shape of the caudal lobes supporting the male membranous bursa (Moravec, 1982, 2001a; Moravec \& Beveridge, 2017). However, as indicated by recent studies, there is certain interspecific variability in this feature and, sometimes, it is difficult to decide whether the species belongs to one or the other genus. Consequently, it cannot be excluded that, on the basis of subsequent studies, Paracapillaria will be synonymised with Capillostrongyloides (see Santos et al., 2008). In having the stichosome consisting of a single row of stichocytes, the absence of lateral caudal alae in the male, presence of a welldeveloped bursa supported by two lateral digital processes (rays), each of them bearing a 
papilla at its base, and with a non- spiny spicular sheath, the specimens of the present material belong to Paracapillaria.

Species of the genus Paracapillaria parasitise fishes and amphibians (subgenus Paracapillaria Mendonça, 1963), reptiles (snakes) (subgenus Ophidiocapillaria Moravec, 1986) and a single species, P. philippinensis (Chitwood, Velasquez \& Salazar, 1968), is known from birds and mammals including man (subgenus Crossicapillaria Moravec, 2001) (Moravec, 2001a, b). To date, a total of 13 species and one subspecies are assigned to Paracapillaria (Paracapillaria). Of them, P. spratti (Moravec \& Sey, 1986) and P. malayensis Moravec, Modrý \& Jirků, 2007 were described from the small intestine of anuran amphibians in Papua New Guinea and the Malayan Peninsula, respectively (Moravec \& Sey, 1986; Moravec et al., 2007), whereas all others have been reported as parasites of fishes. Three species of the subgenus Paracapillaria, P. piscicola (Travassos, Artigas \& Pereira, 1928), P. plectroplites (Johnston \& Mawson, 1940) and P. rhamdiae Moravec, GonzalezSolis \& Vargas-Vazquez, 1995, are gastrointestinal parasites of fresh- water fishes in Brazil, Australia and Mexico, respectively (Moravec, 1987, 2001a; Moravec et al., 1995). Two species and one subspecies, P. teixeirafreitasi (Caballero, 1971), P. teixeirafreitasi pacifica Moravec, Salgado-Maldonado \& Caspeta-Mandujano, 1999 and P. xenentodoni De \& Maity, 1994, are reported as gastrointestinal parasites of brackish-water (estuarine) fishes in Mexico and India (Caballero, 1971; De \& Maity, 1994; Moravec et al., 1999) and six species, P. argentinensis Timi, Rossin, Lanfranchi \& Etchegoin, 2007, P. epinepheli Moravec, Mendoza-Franco \& Vargas-Vazquez, 1996, P. gibsoni Moravec, 1987, P. helenae (Layman, 1930), P. parophrysi (Moravec, Margolis \& McDonald, 1981) and P. sesokoensis Hasegawa, Williams \& Bunkley-Williams, 1991, are described from the stomach or intestine of marine fishes in the Atlantic or Pacific regions (Layman, 1930; Moravec et al., 1981, 1996; Moravec, 1987; Hasegawa et al., 1991; Timi et al., 2007).

As compared with the six Paracapillaria (Paracapillaria) species parasitising marine fishes, the spicule of $P$. gastrica $\mathrm{n}$. sp. is distinctly longer $(267 \mu \mathrm{m})$ than that of $P$. epinepheli $(180-195 \mu \mathrm{m})$, P. helenae $(203 \mu \mathrm{m})$ and $P$. sesokoensis $(95-100 \mu \mathrm{m})$, or distinctly shorter than in $P$. gibsoni $(450-480 \mu \mathrm{m})$. By the spicule length, $P$. argentinensis $(250-370 \mu \mathrm{m})$ and P. parophrysi $(281-373 \mu \mathrm{m})$ are somewhat similar to the new species, but both of them have larger eggs (58-70 x 23-30 $\mu \mathrm{m}$ and 64-71 x 25-30 $\mu \mathrm{m}$, respectively, vs 54-60 x 24-27 $\mu \mathrm{m})$ and their caudal bursa is short, with short lateral lobes adhering to the posterior border of body (vs caudal bursa longer, with lateral digital projections (rays) curved to the median line in ventral view).

The spicule lengths of Paracapillaria (Paracapillaria) species from brackish-water fishes are similar to that of $P$. gastrica n. sp., but $P$. xenentodoni differs from the new species in having smaller eggs (40-49 21-26 $\mu \mathrm{m})$ and a short bursa with short lateral lobes adhering to the posterior border of body. The gravid females of $P$. teixeirai and P. teixeirai pacifica are at most $7.5 \mathrm{~mm}$ long (vs $11.7-15.9 \mathrm{~mm}$ in the new species) and these have usually 
smaller eggs.

Regarding the three species of the subgenus Paracapillaria from freshwater fishes, $P$. rhamdiae distinctly differs from the new species in having a conspicuously short spicule (87 $\mu \mathrm{m}$ long), whereas the gravid females of $P$. plectroplites and $P$. piscicola are at most about $8 \mathrm{~mm}$ long and they have usually smaller eggs. Each of the two Paracapillaria (Paracapillaria) species parasitic in amphibians, $P$. malayensis and P. spratti, possesses a somewhat longer spicule ( $336 \mu \mathrm{m}$ and $309 \mu \mathrm{m}$, respectively vs $267 \mu \mathrm{m}$ ), their caudal bursa is short, with short lateral lobes adhering to the posterior border of body, the female tail is distinctly subterminal (vs almost terminal) and their eggs are with protruding polar plugs (vs eggs with non-protruding polar plugs). In contrast to all Paracapillaria (Paracapillaria) spp. except for $P$. malayensis, the proximal spicule end of $P$. gastrica $\mathrm{n}$. $\mathrm{sp}$. is expanded to form a conspicuous folded, lobular rim. For differences of Paracapillaria species belonging to the subgenera Crossicapillaria and Ophidiocapillaria see Moravec (2001a).

Paracapillaria gastrica $\mathrm{n}$. sp. is so far the only nominal capillariid species known to parasitise a host of the fish order Aulopiformes and the first species of this genus recorded from marine fishes in New Caledonian waters. In New Caledonia, Moravec \& Justine (2010) reported capillariid females designated as Capillariidae gen. sp. 2 from the congeneric host Synodus dermatogenys Fowler, which most probably belonged to this new species.

Acknowledgements We wish to thank Eva Řehulková and Nadia Musilová who helped for the parasitological survey of infected fish; other students and colleagues involved in the parasitological survey were listed in Justine et al. (2010, 2012b). The infected fish was identified by Barry Russel, Charles Darwin University, Australia. Thanks are also due to the Laboratory of Electron Microscopy, Institute of Parasitology, Biology Centre CAS, institution supported by the MEYS CR (LM2015062 Czech-BioImaging) for their support with obtaining scientific data presented in this paper, and to Blanka Škoríková of the same Institute for help with the illustrations.

Funding This study was partly supported by the institutional support of the Institute of Parasitology, BC AS CR (585110/ 9500).

Conflict of interest The authors declare that they have no conflict of interest. 


\section{References}

Caballero, G. (1971). Contribucion al conocimiento de los nematodos de peces de los litorales de Mexico. I. Una nueva especie de Capillaria. Revista Ibérica de Parasitologia, 31, 121-128.

De, N. C., \& Maity, R. N. (1994). Paracapillaria xenentodoni n. sp. (Nematoda: Trichuroidea) from the fish Xenentodon cancila (Hamilton) from West Bengal, India. Systematic Parasitology, 27, 71-75.

Froese, R., \& Pauly, D. (Eds) (2019). FishBase. World Wide Web electronic publication. http://www.fishbase.org, version 11/2019.

Hasegawa, H., Williams, E. H., \& Bunkley-Williams, L. (1991). Nematode parasites from marine fishes of Okinawa, Japan. Journal of the Helminthological Society of Washington, 58, 186-197.

ICZN (2012). International Commission on Zoological Nomenclature: Amendment of articles 8, 9, 10, 21 and 78 of the International Code of Zoological Nomenclature to expand and refine methods of publication. Bulletin of Zoological Nomenclature, 69, 161-169.

Justine, J.-L., Beveridge, I., Boxshall, G. A., Bray, R. A., Moravec, F., Trilles, J.-P., et al. (2010). An annotated list of parasites (Isopoda, Copepoda, Monogenea, Digenea, Cestoda and Nematoda) collected in groupers (Serranidae, Epinephelinae) in New Caledonia emphasizes parasite biodiversity in coral reef fish. Folia Parasitologica, 57, 237-262.

Justine, J.-L., Briand, M. J., \& Bray, R. A. (2012a). A quick and simple method, usable in the field, for collecting parasites in suitable condition for both morphological and molecular studies. Parasitology Research, 111, 341-351.

Justine, J.-L., Beveridge, I., Boxshall, G. A., Bray, R. A., Miller, T. L., Moravec, F., et al. (2012b). An annotated list of fish parasites (Isopoda, Copepoda, Monogenea, Digenea, Cestoda, Nematoda) collected from snappers and bream (Lutjanidae, Nemipteridae, Caesionidae) in New Caledonia confirms high parasite biodiversity on coral reef fish. Aquatic Biosystems, 8, 22.

Layman, E. M. (1930). [Parasitic worms from fishes of Peter the Great Bay.] Izvestiya 
Tikhookeanskoy Nauchno-Promyslovoy Stantsii, 3, 1-120 (In Russian).

Moravec, F. (1982). Proposal of a new systematic arrangement of nematodes of the family Capillariidae. Folia Parasitologica, 29, 119-132.

Moravec, F. (1987). Revision of capillariid nematodes (subfamily Capillariinae) parasitic in fishes. Studie ČSAV No. 3. Prague: Academia, 141 pp.

Moravec, F. (2001a). Trichinelloid nematodes parasitic in cold- blooded vertebrates. Prague: Academia, 429 pp.

Moravec, F. (2001b). Redescription and systematic status of Capillaria philippinensis, an intestinal parasite of human beings. Journal of Parasitology, 87, 161-164.

Moravec, F., \& Beveridge, I. (2017). Lobocapillaria austropacifica n. g., n. sp. (Nematoda: Capillariidae) from the obtuse barracuda Sphyraena obtusata Cuvier (Sphyraenidae, Perciformes) off eastern Australia. Systematic Parasitology, 94, 547-556.

Moravec, F., Gey, D., \& Justine, J.-L. (2016). Nematode parasites of four species of Carangoides (Osteichthyes: Carangidae) in New Caledonian waters, with a description of Philometra dispar n. sp. (Philometridae). Parasite, 23, 40.

Moravec, F., Gonzalez-Solis, D., \& Vargas-Vazquez, J. (1995). Paracapillaria rhamdiae sp. n. (Nematoda: Capillariidae) from Rhamdia guatemalensis (Pisces) in Yucatan, Mexico. Parasite, 2, 235-238.

Moravec, F., \& Justine, J.-L. (2010). Some trichinelloid nematodes from marine fishes off New Caledonia, including description of Pseudocapillaria novaecaledoniensis sp. nov. (Capillariidae). Acta Parasitologica, 55, 71-80.

Moravec, F., \& Justine, J.-L. (2014). Capillaria plectropomi n. sp. (Nematoda: Capillariidae), a new intestinal parasite of the leopard coral grouper Plectropomus leopardus (Serranidae) off New Caledonia. Parasite, 21, 76.

Moravec, F., Margolis, L., \& McDonald, T. E. (1981). Two new species of nematodes of the genus Capillaria (C. freemani sp. nov. and C. parophrysi sp. nov.) from marine fishes of the Pacific coast of Canada. Canadian Journal of Zoology, 59, 8187. 
Moravec, F., Mendoza-Franco, E., \& Vargas-Vazquez, J. (1996). Paracapillaria epinepheli n. sp. (Nematoda: Capillariidae) from the red grouper Epinephelus morio (Pisces) from Mexico. Systematic Parasitology, 33, 149-153.

Moravec, F., Modrý, D., \& Jirků, M. (2007). A new species of Paracapillaria (Nematoda: Capillariidae) from the intestine of the toad Duttaphrynus melanostictus (Anura) from the Malayan Peninsula. Journal of Parasitology, 93, 907-909.

Moravec, F., Salgado-Maldonado, G., \& Caspeta-Mandujano, J. (1999). Capillariids (Nematoda, Capillariidae) from Agonostomus monticola and Gobiomorus spp. (Pisces: Mugilidae and Eleotridae) from fresh waters in Mexico. Acta Parasitologica, 44, 180-187.

Moravec, F., \& Sey, O. (1986). Three new nematode species from Phrynomantis spp. (Amphibia: Microhylidae) from Papua New Guinea. Folia Parasitologica, 33, 343351.

Santos, C. P., Moravec, F., \& Venturieri, R. (2008). Capillostrongyloides arapaimae sp. n. (Nematoda: Capillariidae), a new intestinal parasite of the arapaima Arapaima gigas from the Brazilian Amazon. Memorias do Instituto Oswaldo Cruz, 103, 392-395.

Timi, J. T., Rossin, M. A., Lanfranchi, A. L., \& Etchegoin, J. A. (2007). A new species of Paracapillaria (Nematoda: Capillariidae) parasitizing the Brazilian sandperch, Pinguipes brasilianus (Pisces: Pinguipedidae), from Argentina. Journal of Parasitology, 93, 922-924. 
Fig. 1 Paracapillaria gastrica n. sp. A, Anterior end of female; B, Region of vulva, lateral view; C, Stichocyte at posterior part of female stichosome; D, E, Caudal end of male, ventral and lateral views, respectively; F, Posterior end of male, ventral view; G, Posterior end of male, ventral view (larger magnification); I, Posterior end of female, lateral view; J, egg; K-M, Proximal end, middle part and distal end of spicule, respectively, lateral views; N, Caudal end of female, lateral view

Fig. 2 Paracapillaria gastrica n. sp., scanning electron micrographs. A, Cephalic end of female, sublateral view (arrows indicate cephalic papillae); B, Transverse striations on cuticle at anterior portion of body; C, D, Caudal end of male, ventral and sublateral views; E, Posterior end of male, ventral view; F, Posterior end of female, lateral view (note minute cuticular bosses of lateral bacillary band); G, Caudal end of female, lateral view. Abbreviations: a, anus; b, caudal bursa; c, cloacal aperture; $\mathrm{p}$, adanal papilla 
Figure 1
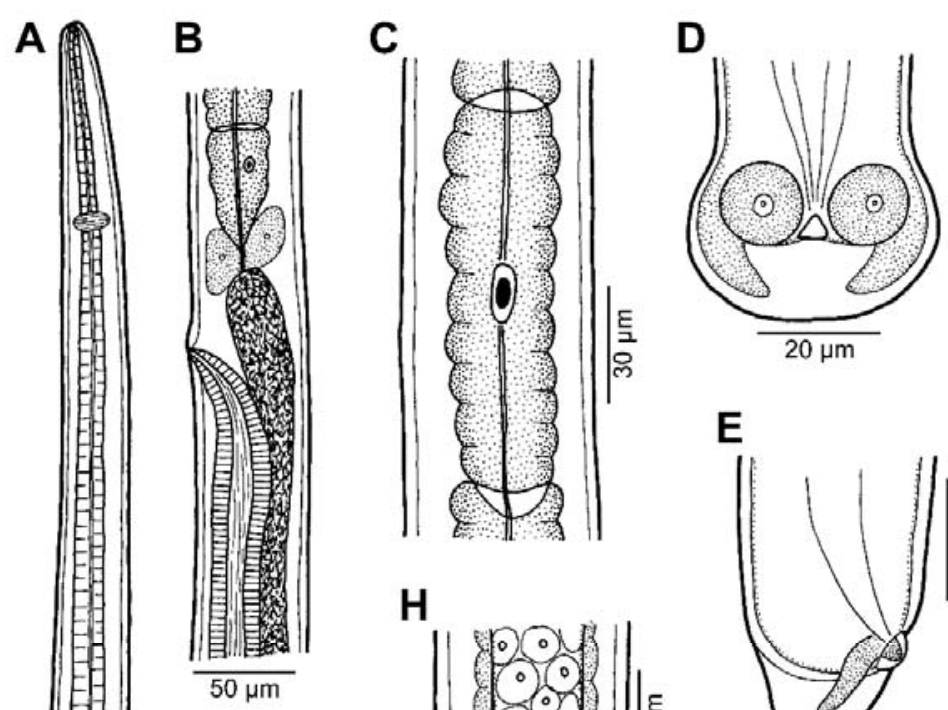

F

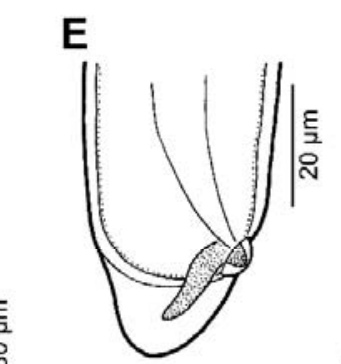

H
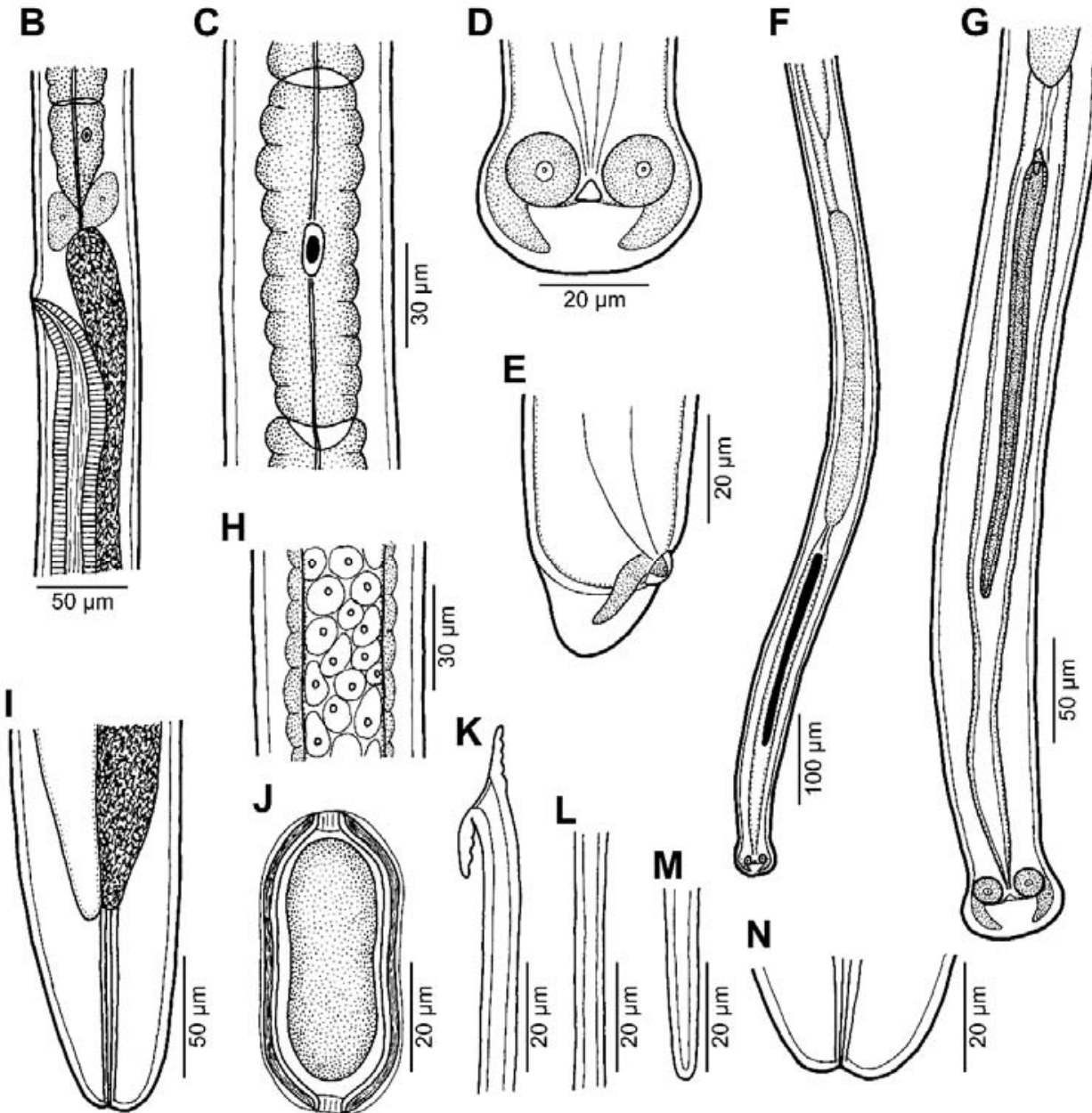
Figure 2

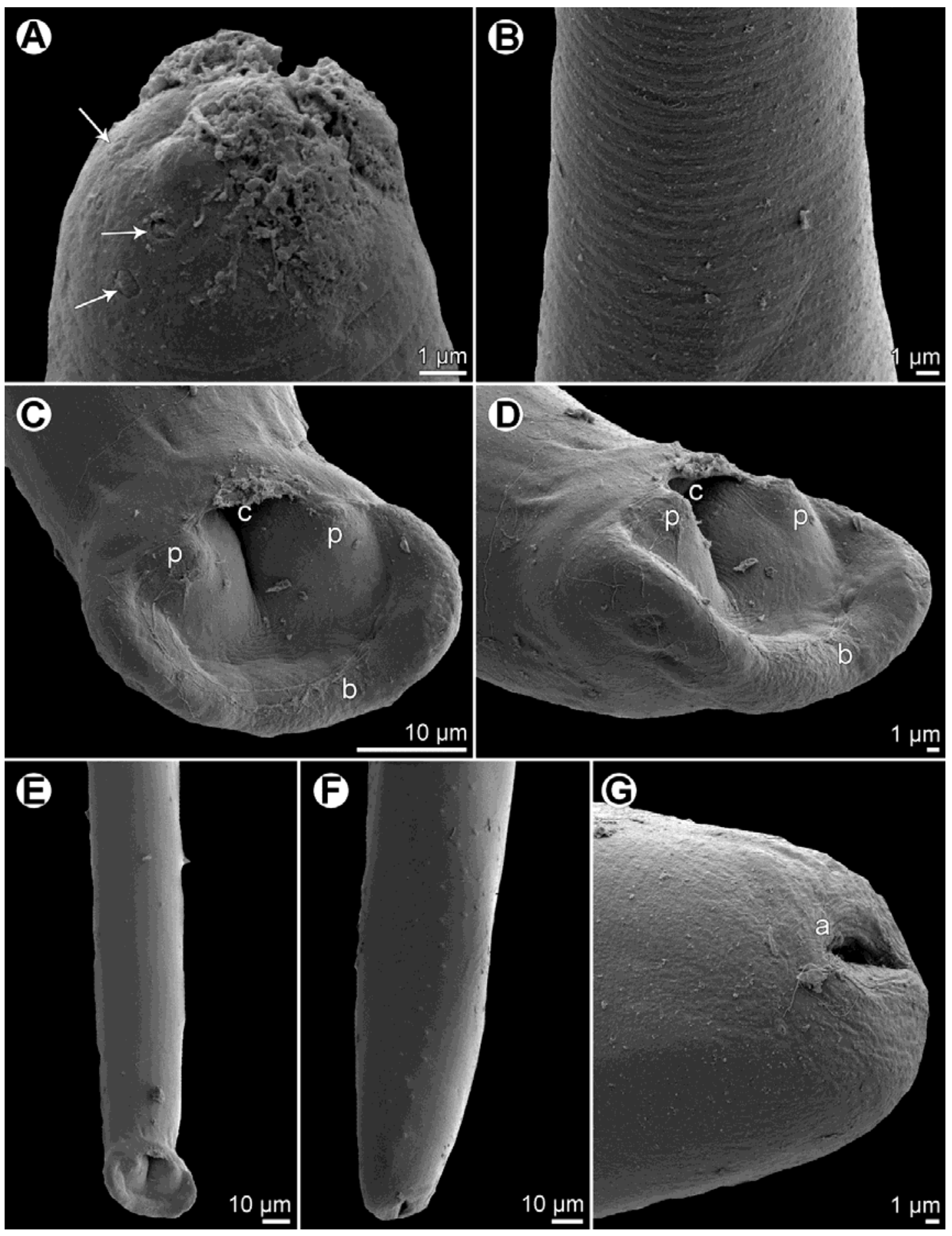

